\title{
Anti-CEACAM6 AFAIKL2 Antibody Fragment/Jack Bean Urease Immunoconjugate L-DOS47
}

National Cancer Institute

\section{Source}

National Cancer Institute. Anti-CEACAM6 AFAIKL2 Antibody Fragment/Jack Bean Urease

Immunoconjugate L-DOS47. NCI Thesaurus. Code C120068.

A lyophilized formulation of DOS47, an immunoconjug ate composed of AFAIKL2, a recombinant camelid single-domain antibody which recognizes carcinoembryonic antigen-related cell adhesion molecule 6 (CEACAM6), and the enzyme urease derived from the plant Canavalia ensiformis (Jack bean), with potential antineoplastic activity. Upon intravenous administration, the AFAIKL2 antibody fragment moiety of L-DOS47 specifically targets and binds to CEACAM6 expressed on certain tumor cells. In turn, the urease moiety of L-DOS47 catalyzes the hydrolysis of urea into ammonia, which is further hydrolyzed to produce hydroxyl ions, and causes a locally increased concentration of the toxic waste product ammonia, which under normal conditions is converted into the nontoxic substance urea via the urea cycle. This increases the $\mathrm{pH}$ of the tumor microenvironment and alkalinizes the highly acidic environment that is needed for cancer cell survival and proliferation. In addition, the ammonia diffuses into cancer cells and exerts a cytotoxic effect. Altogether, this leads to cell death of CEACAM6-expressing cancer cells. The naturally-occurring enzyme urease catalyzes the hydrolysis of urea into ammonia and carbon dioxide. CEACAM6, a tumor-associated antigen and CEA family member, is overexpressed in a variety of tumor cells and plays a key role in tumor initiation, progression, metastasis and survival. 